\title{
Analysis of the systems of balance in elderly practitioners of modalities of yoga, gymnastics and stretching of the Exercise Orientation Service in Vitória/ES
}

\author{
Análise dos sistemas de controle do equilíbrio em idosos praticantes das \\ modalidades ioga, ginástica e alongamento do Serviço de Orientação ao \\ Exercício de Vitória/ES
}

\author{
Jean Leite Cruz', Milena Razuk', Victor Anthony Mendes Ferreira', Leonardo Araujo \\ Vieira $^{1,2}$, Natalia Madalena Rinaldi ${ }^{1}$ \\ 1.Biomechanical Analysis of Movement Laboratory (Bio.Mov), Physical Education and Sports Center, Federal University of \\ Espírito Santo - CEFD/UFES, ES, Brazil. \\ 2. Vitória City Hall, ES, Brazil.
}

\begin{abstract}
Different motor interventions have been widely investigated in balance control in elderly. However, it is not yet clear which type of motor intervention promotes improvements in balance control systems in the elderly. The aim of this study was to compare different motor interventions of the balance control system in elderly. Fifty-six elderly people participated in the study, distributed in sedentary group (SED), gymnastic group (GG), yoga group (GI) and stretching group (GA). Participants were evaluated using the Balance Evaluation System Test (BESTest) tool, designed to evaluate six items of balance control systems. The variables analyzed in the study were the scores obtained in each of the BESTest items. The results showed that GG and GI presented higher values in BESTest compared to the SED group. Even more, for the item gait stability and stability limits presented higher values compared to the other BESTest items. The conclusion of the study is that elderly gymnastics and yoga practitioners, modalities offered by the Exercise Guidance Service (SOE) can promote benefits to the balance control system in elderly.
\end{abstract}

Key-words: BESTest, Balance, Elderly, Motor intervention.

\begin{abstract}
RESUMO
Diferentes intervenções motoras têm sido amplamente investigadas no controle do equilíbrio em idosos. Entretanto, ainda não está elucidado qual o tipo de intervenção motora que promove melhoras nos sistemas de controle do equilíbrio em idosos. O objetivo do estudo foi comparar diferentes intervenções motoras do sistema de controle do equilíbrio em idosos. Participaram do estudo 56 idosos, distribuídos em grupo sedentário (SED), grupo ginástica (GG), grupo ioga (GI) e grupo alongamento (GA). Os participantes foram avaliados através da ferramenta Balance Evaluation System Test (BESTest), desenvolvida para avaliar seis itens do sistema de controle do equilíbrio. As variáveis analisadas no estudo foram as pontuações obtidas em cada um dos itens do BESTest. Os resultados mostraram que o GG e GI apresentaram valores maiores no BESTest comparado ao grupo SED. Ainda, para os itens estabilidade da marcha e limites de estabilidade apresentaram valores maiores comparados aos demais itens do BESTest. A conclusão do estudo é que idosos praticantes de ginástica
\end{abstract}


e de ioga, modalidades oferecidas pelo Serviço de Orientação ao Exercício (SOE) tem capacidade de promover benefícios ao sistema de controle do equilíbrio em idosos

Palavras-chave: BESTest, Equilíbrio, Idosos, Intervenção motora.

\section{Introduction}

The postural stability control and functional mobility are fundamental for carrying out daily activities. During the aging process, changes in these two aspects can be observed, which can have consequences for movement control, for instance, history of falls [1]. Thus, changes in the sensory systems are related to an erroneous perception about the body positioning in space [3]. Based on these data, it is important to develop motor interventions to improve the control of dynamic static and balance in the elderly in order to reduce the risk of falls in this population. Regarding the static balance control, Li et al. [4] found improvement in the functional reach tests, Berg balance scale and Timed Up \& Go (TUG) in seniors after a period of 26 consecutive weeks of Tai Chi training. However, Lelard et al. [5] evaluated static balance control through the pressure center with eyes open and closed, and speed gait over a 10-meter course. The authors compared a Tai Chi program with a balance training program for three months at a twice a week frequency, and concluded that the intervention period was insufficient to verify variations in gait speed or postural levels in the eyes open and eyes closed condition on both interventions.

Zettergen et al. [6] found an increase in gait speed and an increase in the Berg scale score in the elderly after an 8-week yoga intervention. Still, Oken et al. [7] investigated the effect of yoga training on balance control in the elderly. After the three-month period, these authors found that the elderly were able to remain in unipodal support for a longer time. A study by Zhuang et al. [8] verified the effect of generalized training (balance and flexibility) on walking time (TUG) and functional reach test. After the motor intervention period, the elderly reduced walking time and increased the distance in the functional reach test.

Thus, the results showed beneficial effects of individualized and generalized training, however, it is not yet fully elucidated which is the best type of motor modality (generalized, stretching or yoga) for the control of static and dynamic balance in the elderly. In addition, it would be interesting that these interventions were easily accessible to the population, making it possible to discriminate the benefits of physical activity. In this regard, the SOE (Exercise Orientation Service) is a pioneering service considered a model by the Brazilian Society of Sports Medicine in the area of Physical Activity and Health developed in Vitória city/ES. In this program, physical activities are developed in groups with the objective of improving the quality of life and preventing chronic diseases. There are several modules throughout the city, with trained teachers to serve the population. Gymnastitics, yoga and stretching are activities usually offered in SOE modules.

Regarding the analysis of balance and the elderly, some studies used BERG, TUG, POMA scales, among other existing tests, to evaluate balance [912]. Pimentel and Scheicher [9], for example, compared the risk of falls among sedentary and active elderly people, verifying how the practice of physical exer- 
cise can reflect on the subjects' performance on the Berg scale. The authors found a worse performance in the inactive group, it suggests that regular exercise can interfere with this performance and that active subjects have less chance of falling.

Souza et al. [10] used the Berg scale to assess the balance of elderly women after performing different exercise protocols. The participants were divided into two groups: group A who performed resistance exercises, and group B, who performed proprioceptive exercises. The authors found that both groups showed improvement in balance after intervention, showing that the two protocols generated a significant difference in balance, but when compared, no difference was found between the groups. Thus, it was not possible to determine whether there is a specific type of exercise to improve body balance.

Pavanate et al. [11] verified the balance ratio of elderly women who practice physical activity considering different ages using the Timed Up and Go (TUG). The authors conclude that younger the age better the balance, which further demonstrates the loss of the ability to maintain balance with aging. Carvalho, Pinto and Mota [12] analyzed a relation between fear of falling, balance and physical activity. The Balance assessment was performed using the Performance-Oriented Mobility Assessment (POMA). The authors concluded that the practice of physical activity is associated with better balance performance and less fear of falling. From these theoretical assumptions, it can be concluded that motor intervention promotes benefits for the control of balance in the elderly, however, some questions regarding motor interventions and the types of assessment adopted in these studies need to be better clarified.

In the studies previously presented, the authors used some scales that did not specifically assess the systems involved in balance control. Thus, Horak et al. [13] developed a clinical tool called BESTest (Balance Assessment System Test), whose main use criteria are different systems involved in balance control, in order to identify the underlying deficiencies that contribute to the prejudice of balance. From this assessment, it is possible to identify which balance control systems may be affected by the aging process, helping the health professional, since it would be easier to know where to intervene. Thus, an investigation into the benefits applied by different activities / changes, show the important effects for those who can design and plan a quality intervention capable to produce beneficial changes in the balance control in the elderly.

In this context, the objective of the study was compared with different balance control engines in elderly people who practice physical activity by the Orientation and Exercise Service (gymnastics, yoga and monitoring) with elderly people who do not practice physical activity, making use of an easy to use and low cost tool called Balance Evaluation System Test (BESTest). The hypothesis of the study is that the elderly who performed different motor interventions (gymnastics, yoga and stretching) have a higher score on the BESTest compared to the sedentary groups.

\section{Methods}

\section{Participants}

The population of this study was composed of elderly participants in SOE and the Senior Citizenship Center located in the Jardim da Penha nei- 
ghborhood, which are part of the Unified Health System (SUS) and the Unique System of Social Assistance (SUAS) in the Vitória city/ES. SOE is a program to promote physical activity in operation since 1990, which different types of group exercises are offered, such as: gymnastics, yoga, stretching, among others.

The sample consisted of 56 elderly people divided into four groups, with 1 group of inactive elderly people comprising 14 individuals $(68.92 \pm 6.53$ years) recruited at the Elderly Living Center (Control Group) and 3 active elderly groups participants of activities offered by SOE: Gymnastic Group (GG) with 14 participants (67.36 \pm 6.74 years), Yoga Group (GI) with 13 participants (65.16 \pm 5.14 years) and the Stretching Group (GA) with 15 participants ( $73 \pm 5.12$ years).

The study was approved by the ethics committee research of the Federal University of Espírito Santo, CAAE 563154167.0000.5542. All study participants signed a Free and Informed Consent Form (ICF) according to the rules established in Resolution No. 466/12 of the National Health Council. As an inclusion criterion, all participants should be aged 60 to 80 years old, and have independent gait without the use of auxiliary devices, absence of cognitive, neurological and musculoskeletal diseases that would prevent them from performing motor tasks. Also, for the groups of active elderly people, only elderly people who had exercised for at least 3 months with a weekly frequency of 2 workouts per week lasting approximately 60 minutes per session were included, while in the group of inactive elderly people, only elderly people who had not practiced physical activity for at least 3 months were included.

\section{Experimental procedures}

The Modified Baecke Questionnaire for the elderly [14] was applied to assess the level of physical activity and the types of exercises practiced by the elderly before participating in the study. Moreover, the Mini-Mental State Examination [15] was applied to verify whether the elderly's cognitive functions are preserved.

The Balance Evaluation Test (BESTest) [16] was used to assess balance control systems [16], which consists of a clinical test that makes it possible to evaluate six balance control systems (Table I). This test consists of 27 items, with a total of 36 tasks divided into six sessions, referring to the balance control systems. Each task is scored from 0 to 3 points, with 0 being the worst possible performance and 3 the best possible, and the final score is calculated separately for each session as a percentage [16].

\section{Statistical analysis}

Statistical analyzes were performed using SPSS (Statistical Package for the Social Sciences) software, version 21 (SPSS Inc., Chicago, United States). To verify the normality and homogeneity of the data, the Shapiro Wilk test and the Levene test were used, respectively. Four ANOVAs were performed to compare anthropometric characteristics (height and body mass), scores from Baecke and Mini-Mental assessments between the sedentary group (SED) and the active group: gymnastics (GG), yoga (GI) and stretching (GA). In addition, a two-way ANOVA (group [SED, GG, GI, GA] $\mathrm{x}$ item BESTest [biomechanical restriction; stability limits; anticipatory postural adjustments; postural responses; sensory orientation; gait stability] was performed), to verify the possible 
effects of exercise modalities on balance control. When necessary, post hoc tests with Bonferroni adjustment were performed and for all analyzes a significance level of $\mathrm{p} \leq 0.05$ was adopted.

Table I - Description of the items of the Balance Evaluation Test (BESTest).

\begin{tabular}{ll}
$\begin{array}{l}\text { Items } \\
\begin{array}{l}\text { Biomechanical } \\
\text { restrictions }\end{array}\end{array}$ & $\begin{array}{l}\text { Description and exemples of the tasks } \\
\text { tural alignment, ankle range of motion and hip strength. }\end{array}$ \\
$\begin{array}{l}\text { Stability / verticality } \\
\text { limits }\end{array}$ & $\begin{array}{l}\text { Evaluates the ability to move the body on its support base, leaning } \\
\text { forward and laterally and evaluates the ability to return to the verti- } \\
\text { cal position. }\end{array}$ \\
$\begin{array}{l}\text { Anticipatory postural } \\
\text { adjustments }\end{array}$ & $\begin{array}{l}\text { Evaluates the active movement of the center of mass in anticipa- } \\
\text { tion of the execution of sitting and standing, unipodal posture and } \\
\text { touching the step. }\end{array}$ \\
Postural responses & $\begin{array}{l}\text { Evaluates compensatory step to external front, side and rear distur- } \\
\text { bances. }\end{array}$ \\
Sensory orientation & $\begin{array}{l}\text { Evaluates the increase in postural oscillation under different sen- } \\
\text { sory conditions, such as standing on flat ground or foam with eyes } \\
\text { open or closed. }\end{array}$ \\
Gait stability & $\begin{array}{l}\text { It assesses stability when walking under different conditions, such } \\
\text { as changing speed, looking from side to side and passing over an } \\
\text { obstacle. }\end{array}$ \\
\hline
\end{tabular}

\section{Results}

Table II presents the values of average and standard deviation of anthropometric characteristics, level of physical activity through the Modification Questionnaire for Ages and MiniMental for the active group: stretching (GA), gymnastics (GG), yoga (GI) and sedentary (SED). One-way ANOVA for Baecke revealed significant difference for group ( $F 3.52=3.857, \mathrm{p}<0.014)$. Post hoc tests revealed that GG $(5.26 \pm 3.3)$ had a higher score compared to SED $(2.39 \pm 0.85)$. Still, one-way ANOVA for MiniMental revealed significant difference for group $(\mathrm{F} 3.52=4.421, \mathrm{p}<0.008)$. Post hoc tests revealed that GG $(27.14 \pm 2.79)$ and GI $(27.38 \pm 2.46)$ had a higher score compared to SED $(23.85 \pm 3.65)$.

Table II - Average and standard deviation of anthropometric characteristics, level of physical activity by the Modified Baecke Questionnaire for the Elderly and MiniMental for the active group: GA, GG and GI and sedentary (SED).

\begin{tabular}{llllll} 
Group & Age (in years) & Mass (Kg) & stature (m) & $\begin{array}{l}\text { Baecke } \\
\text { (points) }\end{array}$ & $\begin{array}{l}\text { MiniMental } \\
\text { (points) }\end{array}$ \\
\hline $\begin{array}{l}\text { Stretching (GA) } \\
\text { Gymnastics }\end{array}$ & $73,00 \pm 5,12$ & $64,54 \pm 10,21$ & $1,56 \pm 0,06$ & $3,54 \pm 1,99$ & $26,66 \pm 2,46$ \\
$\begin{array}{l}\text { (GG) } \\
\text { Yoga (GI) }\end{array}$ & $67,36 \pm 6,74$ & $61,59 \pm 7,59$ & $1,57 \pm 0,04$ & $5,26 \pm 3,30$ & $27,14 \pm 2,79$ \\
$\begin{array}{l}\text { Sedentary } \\
\text { (SED) }\end{array}$ & $68,16 \pm 5,14$ & $61,51 \pm 6,52$ & $1,61 \pm 0,03$ & $4,35 \pm 3,30$ & $27,38 \pm 2,46$ \\
Total & $68,82 \pm 6,47$ & $66,65 \pm 13,41$ & $1,59 \pm 0,06$ & $3,90 \pm 2,47$ & $26,25 \pm 3,14$ \\
\hline
\end{tabular}


Figure 1 shows values of average and standard deviation for the items on the BESTest scale for the active group: stretching (GA), gymnastics (GG), yoga (GI) and sedentary (SED). Two-way ANOVA revealed a significant difference for the group $(\mathrm{F} 1.52=9.119 ; \mathrm{p}<0.001)$ and for the BESTtest item (F5.260 $=(64.101, \mathrm{p}<0.001)$. Post hoc tests for the group revealed that GG $(16.53 \pm 0.48$ points) and GI $(16.21 \pm 0.49$ points $)$ showed higher values compared to SED (13.32 \pm 0.48 points).

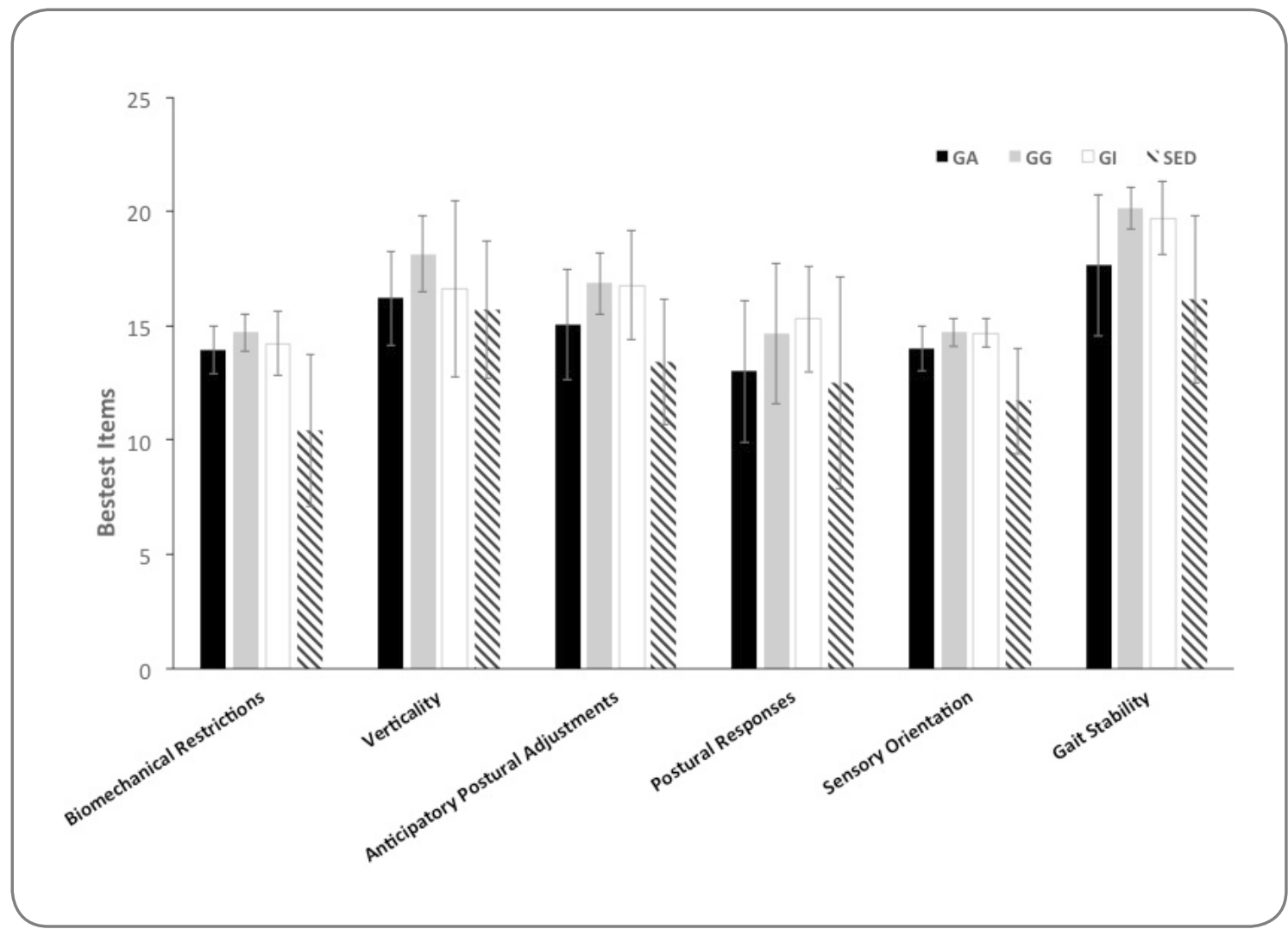

Figure 1 - Average and standard deviation of BESTest items: biomechanical restrictions, limits of stability / verticality, anticipatory postural adjustments, postural responses, sensory orientation, gait stability for the active group: GA, GG and GI and sedentary (SED).

\section{Discussion}

The objective of the present study was to compare the different motor interventions of the balance control system in elderly people who practice physical activity by the Exercise Orientation Service (gymnastics, yoga and stretching) with elderly people who do not practice systematic physical activity, making use of a tool of easy application and low cost, called Balance Evaluation System Test (BESTest).

The main findings of the present study were that the GG $(16.53 \pm 0.48)$ and GI $(16.21 \pm 0.49)$ groups had a higher BESTest score when compared to the sedentary group (SED) $(13.32 \pm 0.48)$. Still, the elderly had a higher score in the items gait stability $(18.37 \pm 3)$, stability / vertical limits $(16.66 \pm 2.83)$ and anticipatory postural adjustments $(15.5 \pm 2.64)$ compared to the items postural responses $(13.82 \pm 3.51)$, sensory orientation $(13.76 \pm 1.78)$ and biomechanical restrictions $(13.32 \pm 2.53)$.

The modified Baecke Questionnaire for the elderly revealed that the activity level of the GG group was higher compared to the SED group, which was 
already expected. However, this was not observed in the yoga and stretching modalities, suggesting that the intensity of both was not capable of promoting significant levels of physical activity, remaining at a level like the SED group. Finally, in the Mini-Mental State Exam, the elderly in the GG and GI group had higher values than the GA and SED group. This means that physical activity, promoted by these two modalities (gymnastics and yoga), may be able to act on the practitioner's cognitive abilities, and can be a good ally during the aging process.

The study by O'Hoski et al. [17] showed a moderate relation to the rising of balance Evaluation System Test (BESTest) with physical activity in the elderly. Therefore, O'Hoski et al. [17] reinforce the results found in the present study, because the active group practicing gymnastics and yoga shows the best performance in BESTest when compared to elderly people who do not practice systematic physical activity. Thus, the result of the present study can be justified due to the fact that gymnastics and yoga classes include exercises performed on different support bases (bipedal and unipodal), multidirectional movements (walking forward, backward and laterally), it can therefore contribute to the improvement in the postural balance control system. In this context, Shanahan et al. [18] showed that elderly practitioners of ballroom dance also performed better in the Balance Assessment System Test (BESTest) when compared to elderly non-dance practitioners. The authors justify that dance, like any systematized physical activity program, contemplates several factors that can bring benefits to the postural balance control system, such as repetitive multidirectional movements [18].

In the present study, the active elderly participants in the motor stretching intervention presented similar behavior at BESTest when compared to the group that did not practice systematic physical activity. Chiacchiero et al. [19] evaluated the range of motion for flexion, extension, abduction, adduction, internal and external rotation of the hip; knee flexion and extension; and plantar flexion, dorsiflexion, inversion and eversion of the ankle using a goniometer. Although the authors report the study's limitation in evaluating the postural balance system using only two functional tests (Timed Get Up and Go and Functional Reach Test), no relation was found between ranges of motion of the joints assessed with the balance test [19]. From these results, it is suggested that motor intervention in which the main objective is only in gaining range of motion does not promote benefits in the postural balance control system.

It is curious that all the elderly presented a worse perform in three of the six items of the Balance Evaluation System Test (BESTtest), with the following items: biomechanical restrictions, postural responses and sensory guidance. Thus, it is possible to infer which are the categories with the highest level of difficulty in the tasks evaluated, because it involves conditions not experienced daily, especially for elderly people who have advanced age and changes in sensory and motor systems. Makey and Robinovitch [20] examined the relative importance of strength (peak angular torque) and response speed (reaction time) in the ability of individuals to use the ankle strategy to regain balance from a determined angle of body inclination. When comparing young and elderly, the results indicate that both strength and speed of response are lower for the elderly. The authors suggested that the delay in response time was due to differences in the perception of the stimulus and in the processing of the motor commands. This can be explained due to neuronal factors such as the 
reduction in the number of motor units, the decrease in the number of motor neurons found in the spinal cord and the reduction in the capacity of the central nervous system to send nerve impulses and activate the motor units [21]. The decrease of strength and the increase of time to produce maximum strength can lead to an inability to generate adequate torque in the joints responsible for maintaining posture.

Regarding to the worst performance of the elderly in the item Sensory Orientation of the Balance Evaluation System Test (BESTtest), it may be due to changes in the sensory systems, mainly in the somatosensory, visual and vestibular systems resulting from the aging process that can provide reduced and inappropriate sensory information for the postural control system. Several studies [22-25] have investigated the contribution of the visual system to postural control through manipulations of this system and the verification of the postural response triggered by this manipulation [25]. It is simple to manipulate the visual system, since the simple act of closing your eyes is enough to observe changes in postural control. According to a literature review conducted by Maki and Mcllroy [26], elderly people have reduced visual acuity, contrast sensitivity, depth perception and adaptation in dark environments. In addition, there is a decrease in the ability to detect changes in the direction of the optical flow. As a consequence of these changes, the elderly have difficulty perceiving changes in the environment, such as changes in the characteristics of the floor, unevenness and obstacles [27], which can have consequences for the control of balance, such as a history of falls. Thus, the Balance Evaluation System Test (BESTest), by offering a complete assessment, encompassing different systems, makes it more reliable to track and identify the system that is most affected and that wants more attention for future interventions aimed at improving postural balance. Thus, this tool shows great potential as an ally in assessments of the balance control system in the elderly.

If possible, future researches should carry out a pre- and post-training investigation of the modalities offered by SOE, in order to be clearly evidenced possible changes caused by each of the practices and, also, observe the necessary practice time so that the practitioners can benefit from such changes.

An important service limiting that must be taken into account is the fact that the training control is not carried out regarding the progression (overload) and training intensity for example. In this way, a training that offers this control can provide more accurate data about the changes and adaptations promoted to the participants.

\section{Conclusion}

Regarding to the evaluated modalities, we can conclude that the gymnastic and yoga modalities, offered by the Exercise Orientation Service of Vitória City/ES, held twice a week with an approximate duration of 60 minutes per session, has the capacity to promote positive gains in balance systems in the elderly practitioners population, reducing the risk of falls and, consequently, helping to improve the quality of life. 


\section{References}

1. Rubenstein LZ. Falls in older people: epidemiology, risk factors and strategies for prevention. Age Ageing 2006;3591):37-41. https://doi.org/ 10.1093/ageing/aflos4

2. Melzer I, Benjuya J, Kaplanski J. Postural stability in the elderly: a comparison between fallers and non-fallers. Age Ageing 2004;33(6):602-7. https://doi.org/10.1093/ageing/afh218

3. Pasma JH, Engelhart D, Schouten AC, Van der Kooij H, Maier AB, Meskers CGM. Impaired standing balance: the clinical need for closing the loop. Neuroscience 2015;267:157-65. https:// doi.org/10.1016/j.neuroscience.2014.02.030.

4. Li F, Harmer P, Fisher KJ, McAuley E, Chaumeton N, Eckstrom E, Wilson NL. Tai Chi and fall reductions in older adults: a randomized controlled trial. J Gerontol A Biol Sci Med Sci 2005;60:187-94. https://doi.org/10.1093/gerona/60.2.187

5. Lelard T, Doutrellot PL, David P, Ahmaidi S. Effects of a 12-week Tai Chi Chuan program versus a balance training program on postural control and walking ability in older people. Arch Phys Med Rehabil 2010;91(1):9-14. https://doi.org/10.1016/j.apmr.2009.09.014.

6. Zettergren KK, Lubeski JM, Viverito JM. Effects of a yoga program on postural control, mobility, and gait speed in community-living older adults: a pilot study. J Geriatric Phys Ther 2011;34:88-94. https://doi.org/10.1519/JPT.0b013e31820aab53.

7. Oken BS, Zajdel D, Kishiyama S, Flegal K, Dehen C, Haas M et al. Randomized, controlled, six-month trial of yoga in healthy seniors: effects on cognition and quality of life. Altern Ther Health Med 2006;12:40-7.

8. Zhuang J, Huang L, Wu Y, Zhang Y. The effectiveness of a combined exercise intervention on physical fitness factors related to falls in community-dwelling older adults. Clinical Intervention Aging 2014;9:131-40. https://doi.org/10.2147/CIA.S56682

9. Pimentel RM, Scheicher ME. Comparação do risco de queda em idosos sedentários e ativos por meio da escala de equilíbrio de Berg. Fisioter Pesqui 2009;16(1):6-10. https://doi. org/10.1590/S1809-29502009000100002

10. Souza CM et al. Equilíbrio de idosas após aplicação de diferentes protocolos de exercícios. Semina: Ciências Biológicas e da Saúde 2019 ;39(2):153-60. http://doi.org/10.5433/ 1679-0367.2018v39n2p153

11. Pavanate AA, Hauser E, Goncalves AK, Mazo GZ et al. Avaliação do equilíbrio corporal em idosas praticantes de atividade física segundo a idade. Rev Bras Ciênc Esporte 2018;40(4):404-9. https://doi.org/10.1016/j.rbce.2018.03.023.

12. Carvalho J, Pinto J, Mota J. Actividade física, equilíbrio e medo de cair. Um estudo em idosos institucionalizados. Rev Port Ciênc Desp 2007;7(2):225-31.

13. Horak FB, Wrisley DM, Frank J. The Balance Evaluation Systems Test (BESTest) to differentiate balance deficits. Phys Ther 2009;89:484-98. https://doi.org/ 10.2522/ptj.20080071.

14. Voorrips LE, Ravelli AC, Dongelmans PC, Deurenberg P, Van Staveren WA. A physical activity questionnaire for the elderly. Med Sci Sports Exerc 1997;29:117-21.

15. Brucki SMD, Nitrini R, Caramelli P, Bertolucci PHF, Okamoto IH. Suggestions for utilization of the mini-mental state examination in Brazil. Arqui Neuro-Psiquiatr 2003;61(3-B):777-81. https://doi.org/10.1590/S0004-282X2003000500014

16. Maia AC, Rodrigues-de-Paula F, Magalhães LC, Teixeira RLL. Cross-cultural adaptation and analysis of the psychometric properties of the Balance Evaluation Systems Test and MiniBESTest in the elderly and individuals with Parkinson's disease: application of the Rasch model. Braz J Phys Ther 2013;17(3):195-217. https://doi.org/10.1590/S1413-35552012005000085

17. O'Hoski S, Sibley KM, Brooks D, Beauchamp MK. Construct validity of the BESTest, mini-BESTest and briefBESTest in adults aged 50 years and older. Gait \& Posture 2015;42:301-5. https://doi.org/10.1016/j.gaitpost.2015.06.006.

18. Shanahan J, Coman L, Ryan F, Saunders J, O'Sullivan K, Ni Bhriain O, Clifford AM. To dance or not to dance? A comparison of balance, physical fitness and quality of life in older Irish set dancers and age-matched controls. Public Health 2016;56-62. https://doi.org/10.1016/j. puhe.2016.07.015

19. Chiacchiero M, Dresely B, Silva U, Delosreyes R, Vorik B. The relationship between ran- 
ge of movement, flexibility, and balance in the elderly. Topics in Geriatric Rehabilitation 2010;26(2):147-54.

20. Mackey DC, Robinovitch SN. Mechanisms underlying age-related differences in ability to recover balance with the ankle strategy. Gait and Posture 2006;23:59-68. https://doi.org/10.1016/j. gaitpost.2004.11.009

21. Häkkinen K, Pastinen UM, Karsikas R, Linnamo V. Neuromuscular performance in voluntary bilateral and unilateral contraction and during electrical stimulation in men at different ages. Eur J Appl Physiol 1995;70:518-27. https://doi.org/10.1007/bf00634381

22. Engelhart DE, Pasma JH, Schouten AC. et al. Impaired standing balance in elderly: a new engineering method helps to unravel causes and effects. J Am Med Dir Assoc 2014;15:221-27. https://doi.org/10.1016/j.jamda.2013.09.009.

23. Hay L, Bard C, Fleury M. Availability of visual and proprioceptive afferent messages and postural control in elderly adults. Exp Brain Res 1996;108:129-39.

24. Prieto TE, Myklebust JB, Hoffman RG et al. Measures of postural steadiness: Differences between healthy young and elderly adults. IEEE Trans Biomed Eng 1996;43:956-66, 1996. https:// doi.org/10.1109/10.532130

25. Teasdale N, Stelmach GE, Breunig A. Postural sway characteristics of the elderly under normal and altered visual and support surface conditions. J Gerontol 1991;46:238-44. https://doi. org/10.1093/geronj/46.6.B238

26. Maki BE, Mcilroy WE. Postural control in the older adult. Clin Geriatr Med 1996;12(4):635-58. 27. Lord SR, Clark RD, Webster IW. Postural stability and associated physiological factors in a population of aged persons. J Gerontol 1991;46(2):69-76. https://doi.org/10.1093/geronj/46.3.m69 